\title{
Successful management of severe intrahepatic cholestasis of pregnancy: report of a first Japanese case
}

\author{
Kenya Kamimura $^{1 * \dagger}$, Hiroyuki Abe ${ }^{1 \dagger}$, Naomi Kamimura ${ }^{2 \dagger}$, Masayuki Yamaguchi ${ }^{2}$, Maiko Mamizu$^{1}$, Kanna Ogi $^{2}$, \\ Yoshifumi Takahashi ${ }^{1}$, Ken-ichi Mizuno ${ }^{1}$, Hiroteru Kamimura ${ }^{1}$, Yuji Kobayashi ${ }^{1}$, Manabu Takeuchi ${ }^{1}$, \\ Kunihiko Yoshida ${ }^{2}$, Kyoko Yamada ${ }^{2}$, Takayuki Enomoto ${ }^{2}$, Koichi Takakuwa ${ }^{3}$, Minoru Nomoto ${ }^{1}$, Miki Obata ${ }^{4}$, \\ Yoshinori Katsuragi ${ }^{4}$, Yukio Mishima ${ }^{4}$, Ryo Kominami ${ }^{4}$, Tomoteru Kamimura ${ }^{5}$ and Yutaka Aoyagi ${ }^{1}$
}

\begin{abstract}
Background: Intrahepatic cholestasis of pregnancy (ICP) is a cholestasis condition caused by elevated levels of serum bile acids that mainly occurs in the third trimester of pregnancy. Maternal symptoms include pruritus; elevation of transaminases, biliary enzymes, and bilirubin levels; and abnormal liver function tests. Fetal symptoms include spontaneous preterm labor, fetal distress, and intrauterine death. It is more prevalent in the Caucasians and is rarely found in Asian countries, including Japan. The etiology of ICP has been reported as involving various factors such as, environmental factors, hormone balance, and genetic components. The genetic factors include single-nucleotide polymorphisms (SNPS) in the genes of canalicular transporters, including $A B C B 4$ and $A B C B 11$. It has also been reported that the combination of these SNPs induces severe cholestasis and liver dysfunction.
\end{abstract}

Case presentation: Here, we report for the first time a 24-year Japanese case of severe ICP diagnosed by typical symptoms, serum biochemical analysis, and treated with the administration of ursodeoxycholic acid which improved cholestasis and liver injury and prevented fetal death. The sequence analysis showed SNPs reported their association with ICP in the ABCB11 (rs2287622, V444A) and ABCB4 (rs1202283, N168N) loci.

Conclusion: The risk of ICP has been reported to be population-specific, and it is rare in the Japanese population. Our case was successfully treated with ursodeoxycholic acid and the genetic sequence analysis has supported the diagnosis. Because genetic variation in $A B C B 4$ and $A B C B 11$ has also been reported in the Japanese population, we need to be aware of potential ICP cases in pregnant Japanese women although further studies are necessary.

Keywords: Intrahepatic cholestasis of pregnancy, Bile acid, Ursodeoxycholic acid, Single-nucleotide polymorphism, $A B C B 11, A B C B 4$

\section{Background}

The etiology of intrahepatic cholestasis of pregnancy (ICP) involves various factors such as environmental factors, hormonal balance, and genetic components. The relation of the genetic factors lead to the various prevalence rates among different ethnic groups. It has been reported that the prevalence in Caucasians in Europe,

\footnotetext{
* Correspondence: kenya-k@med.niigata-u.ac.jp

${ }^{\dagger}$ Equal contributors

'Division of Gastroenterology and Hepatology, Graduate School of Medical and Dental Sciences, Niigata University, 1-757 Asahimachido-ri, Chuo-ku, Niigata 951-8510, Japan

Full list of author information is available at the end of the article
}

United States, Canada, and Australia ranges from 0.1\% to $1.5 \%$ [1]. On the other hand, much fewer number of cases have been reported in Asian countries [2]. Symptoms include itching, particularly of the palms and feet, and jaundice. Fetal consequences of ICP include spontaneous preterm labor, fetal distress, and intrauterine death due to increased levels of serum bile acids [1-5]. Biochemical analysis shows a mild increase in transaminases, bilirubin, other biliary enzymes, and serum bile acids levels of $>10 \mu \mathrm{mol} / \mathrm{L}$ [6,7]. In addition, the level of cytotoxic bile acids, such as chenodeoxycholic acid, increases 10-100 times higher than the normal level. 
Symptoms and serum abnormalities abate after delivery; however, recently, reviews have reported that ICP is also related to an increased risk of developing hepatobiliary diseases later in life [8]. More recently, results of comprehensive analysis of genetic variation in ICP have been reported, and common variations around $A B C B 4$ and $A B C B 11$ encoding multidrug resistance protein 3 (MDR3) and bile salt export pump (BSEP), respectively, have been reported as key factors $[1,6]$. Similar results have been reported that $A B C B 4$ [9-13] and $A B C B 11$ [14] have significant relationships with the etiology of ICP. The combination of these mutations has been reported to be related to severe ICP. For example, the combination of homozygous polymorphisms in $A B C B 11$ at the complementary DNA position 1331 with a thymine replaced by a cytosine (1331 T > C, rs2287622), leading to an exchange from valine to alanine (V444A), and in $A B C B 4$ at position 959 in exon 9 with a cytosine replaced by a thymine (959 C > T), leading to an exchange of serine to phenylalanine (S320F), and some other synonymous SNPs are considered to be related to the etiology of severe type of ICP [15]. Further analysis has shown that the association of $1331 \mathrm{~T}>\mathrm{C}$ (rs2287622) was also driven by other SNP (rs3815676) [1]. Therefore, these genetic variations may contribute to the difference of the occurrence in ethnic groups and further studies will clarify the more accurate contributions of each variation, since these SNPs have also been found in general population [16-18]. Here, we report the first case of a Japanese woman diagnosed with ICP based on severe pruritis, increased levels of bile acid and hepatobiliary enzymes, and successfully treated with ursodeoxycholic acid (UDCA) preventing fetal death and clinical symptoms as well. The genetic sequence analysis showed a homozygous polymorphism in $A B C B 11$ at $1331 \mathrm{~T}>\mathrm{C}$ leading to V444A that is often reported in the conditions [1,15]. Furthermore, another synonymous single-nucleotide polymorphism in $A B C B 4$ (504 $\mathrm{C}>\mathrm{T}$, rs1202283, N168N) was combined in our patient that have never been reported the association with this disease. Based on these results, we concluded our case as a first Japanese case of severe ICP with mutations in $A B C B 11$ and $A B C B 4$. Further study will help us to find and appropriately treat patients preventing fetal death and clinical symptoms.

\section{Case presentation}

A 24-year-old Japanese pregnant female presented with severe pruritis and jaundice in the 15th week of her first pregnancy and was referred to our department. She had never been diagnosed with a constitutional hyperbilirubinemia. Physical examination revealed skin and conjunctival jaundice. No nausea, vomiting, headache, or fatigue were noted, and her blood pressure and other physiological tests were normal. Laboratory tests revealed the increased levels of direct bilirubin (D-Bil, $4.0 \mathrm{mg} / \mathrm{dl}$ ), aspartate aminotransferase (AST, $264 \mathrm{IU} / \mathrm{l}$ ), alanine aminotransferase (ALT, $545 \mathrm{IU} / \mathrm{l}$ ), and lactate dehydrogenase (LDH, $241 \mathrm{IU} / \mathrm{l})$. Total bile acid level was high $(89.6 \mu \mathrm{mol} / \mathrm{l})$, and the ratio of the cytotoxic chenodeoxycholic acid to total bile acid (C/BA) was 0.24 at the time of admission (Table 1). No hemolysis or decrease in platelet count was observed, and tests for viral markers including hepatitis $\mathrm{A}, \mathrm{B}$, and $\mathrm{C}$ and autoimmune markers including anti-nuclear, anti-mitochondrial, and anti-phospholipid antibodies were negative. Slight increases in AFP ( $\alpha$-fetoprotein) to $36 \mathrm{ng} / \mathrm{ml}$ and AFP-L3 (Lens culinaris agglutinin -reactive $\alpha$-fetoprotein isoform) to $32.8 \%$, which are often found in pregnancy were detected and protein induced by Vitamin $\mathrm{K}$ absence or antagonists-II (PIVKAII) showed normal level (Table 1). No proteinuria or ketonuria was noted on urine tests. Ultrasonography revealed no chronic damage or acute fatty infiltration in the liver. Computed tomography was not utilized due to the pregnancy. The patient's mother had a history of third-trimester pruritis; however, her symptoms were milder, and she had no history of fetal death or preterm delivery. No symptoms were marked in her grandmother. Based on these findings, she was diagnosed with ICP with severe clinical symptoms, although rare in the Japanese population. To support the diagnosis, we obtained the patient's written informed consent and performed genomic sequencing of genes such as $A B C B 4$ and $A B C B 11$, the genetic variations of which have been reported to be related to the etiology and severity of the disease (approved by the ethics committee at the Niigata University, No. 536). Sequencing of all the coding exons of the genes revealed a nonsynonymous homozygous mutation in $A B C B 11$ and a synonymous mutation in

\section{Table 1 Results of laboratory investigation}

\begin{tabular}{|c|c|c|c|c|c|}
\hline \multicolumn{2}{|c|}{ Hematology } & \multicolumn{4}{|c|}{ Biochemistry } \\
\hline WBC & $10,080 / \mu l$ & $\mathrm{TP}$ & $6.8 \mathrm{~g} / \mathrm{dl}$ & TG & 197 mg/dl \\
\hline $\mathrm{RBC}$ & $410 \times 10^{4} / \mu \mathrm{l}$ & Alb & $3.7 \mathrm{~g} / \mathrm{dl}$ & $\mathrm{TC}$ & $191 \mathrm{mg} / \mathrm{dl}$ \\
\hline $\mathrm{Hb}$ & $13.3 \mathrm{~g} / \mathrm{dl}$ & BUN & $8 \mathrm{mg} / \mathrm{dl}$ & $\lg G$ & $908 \mathrm{mg} / \mathrm{dl}$ \\
\hline $\mathrm{Ht}$ & $39.8 \%$ & Cre & $0.36 \mathrm{mg} / \mathrm{dl}$ & CRP & $0.05 \mathrm{mg} / \mathrm{dl}$ \\
\hline \multirow[t]{2}{*}{ PLT } & $25.5 \times 10^{4} / \mu \mathrm{l}$ & T-Bil & $6.3 \mathrm{mg} / \mathrm{dl}$ & Bile acid & $89.6 \mu \mathrm{mol} / \mathrm{l}$ \\
\hline & & D-Bil & $4.0 \mathrm{mg} / \mathrm{dl}$ & $\mathrm{C} / \mathrm{BA}$ & 0.24 \\
\hline \multicolumn{2}{|c|}{ Coagulation } & AST & $264 \mathrm{IU} / \mathrm{I}$ & $\mathrm{HbA1c}$ & $4.2 \%$ \\
\hline \multirow[t]{6}{*}{ PT\% } & $121 \%$ & $\mathrm{ALT}$ & $545 \mathrm{IU} / \mathrm{I}$ & \multicolumn{2}{|c|}{ Serum Marker } \\
\hline & & ALP & $310 \mathrm{IU} / \mathrm{I}$ & AFP & $36 \mathrm{ng} / \mathrm{ml}$ \\
\hline & & $\mathrm{LDH}$ & $241 \mathrm{IU} / \mathrm{I}$ & AFP-L3 & $32.8 \%$ \\
\hline & & Y-GTP & $14 \mathrm{IU} / \mathrm{I}$ & PIVKAll & $44 \mathrm{mAU} / \mathrm{ml}$ \\
\hline & & ChE & $137 \mathrm{IU} / \mathrm{I}$ & ANA & $(-)$ \\
\hline & & & & AMA & $(-)$ \\
\hline
\end{tabular}


$A B C B 4$ (Figure 1). The nonsynonymous polymorphism in $A B C B 11$ was a major single-nucleotide exchange from thymine to cytosine at the position $1331(1331 \mathrm{~T}>\mathrm{C})$, leading to an exchange from valine to alanine (V444A). This has been reported to be strongly associated with ICP based on a large cohort study [1]. The synonymous mutation in $A B C B 4$ was $504 \mathrm{C}>\mathrm{T}$, which has never been reported to be association with the disease.

\section{Clinical course}

After the diagnosis of ICP, the patient was treated with UDCA (300 mg daily) from the 18th day of her admission and the dose was increased to $600 \mathrm{mg}$ daily at 13 weeks after the admission since the level of ALT showed mild increasing pattern (Figure 2). Her pruritis slowly improved, and D-Bil, AST, ALT, and LDH levels slowly decreased to normal ranges after the initiation of the administration of UDCA and returned to the normal levels of $0.6 \mathrm{mg} / \mathrm{dl}$, $17 \mathrm{IU} / \mathrm{l}, 20 \mathrm{IU} / \mathrm{l}$, and $135 \mathrm{IU} / \mathrm{l}$, respectively within 3 weeks after the spontaneous preterm delivery of a healthy and well-developed infant at the 35th week of gestation (Figure 2). Her C/BA ratio decreased to 0.19 (total bile acid level of $270.3 \mu \mathrm{mol} / \mathrm{l}$ ) within 12 weeks and returned to the minimum level of 0.02 (total bile acid level of $42.5 \mu \mathrm{mol} / \mathrm{l}$ ) just after delivery. The administration of UDCA was discontinued 3 weeks after delivery, and no symptom recurrence or increases in the level of hepatobiliary enzymes were observed.

\section{Discussion}

Viral hepatitis, autoimmune liver injury, hyperemesis gravidarum, acute fatty liver of pregnancy, HELLP (hemolysis, elevated liver enzyme levels, and low platelet levels) syndrome, preeclampsia, and ICP are known to be involved in the etiology of liver injury found during pregnancy $[1,6]$. Among these diseases, ICP is frequently found in Caucasians, and the difference in the prevalence rate of ICP among the populations is due to genetic variation in the genes encoding ATP-Binding Cassette (ABC) transporters [2]. The most common symptom is pruritis, which typically presents in the third trimester of pregnancy, but early disease onset can be observed in $\sim 20 \%$ of cases [7]. Symptoms disappear after delivery; however, it has been reported that ICP is associated with an increased risk of developing various hepatobiliary diseases, including gallstones and cirrhosis, later in life [8]. Biochemical analysis revealed increased levels of transaminases, bilirubin, and serum bile acids $(>10 \mu \mathrm{mol} / \mathrm{l})$. However, clinical jaundice is detected in $10 \%-15 \%$ of patients, and bile acid levels rarely exceed $100 \mu \mathrm{mol} / \mathrm{l}[2,5]$. The symptoms and the level of serum enzymes ranged variously, and the severe type was reported with an early onset, severe pruritis, significant elevation of the hepatobiliary enzymes [15].

Recent large cohort studies and reviews reported that common variations around $A B C B 4$ and $A B C B 11$ as key factors for developing ICP [1-6]. In addition, it has been reported that the SNP in $A B C B 11(1331 \mathrm{~T}>\mathrm{C})$, leading to an exchange from valine to alanine (V444A), is related

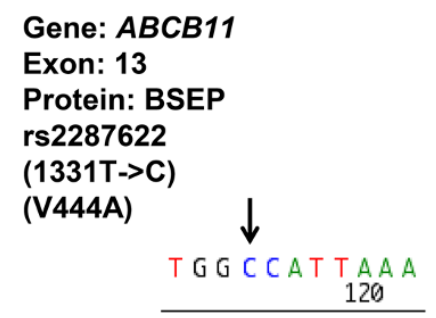

\section{Gene: $A B C B 4$ \\ Exon: 6 \\ Protein: MDR3 \\ rs1202283 \\ (504C->T) \\ (N168N)}

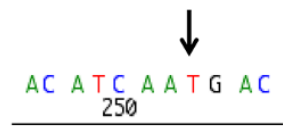

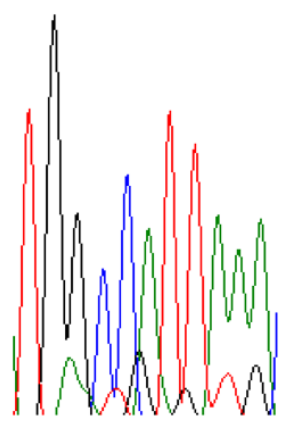

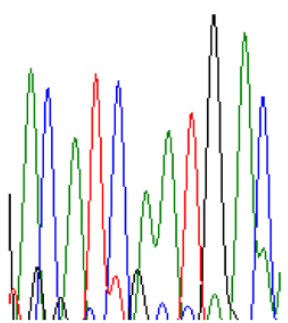

Figure 1 Single-nucleotide polymorphisms in $A B C B 11$ and $A B C B 4$ of the patient. Sequencing of all the coding exons of $A B C B 4$ and $A B C B 11$ was performed with the standard genomic sequencing procedure. Black arrows indicate the mutations found in the patient. Genetic information from the database is shown in the upper panel. 


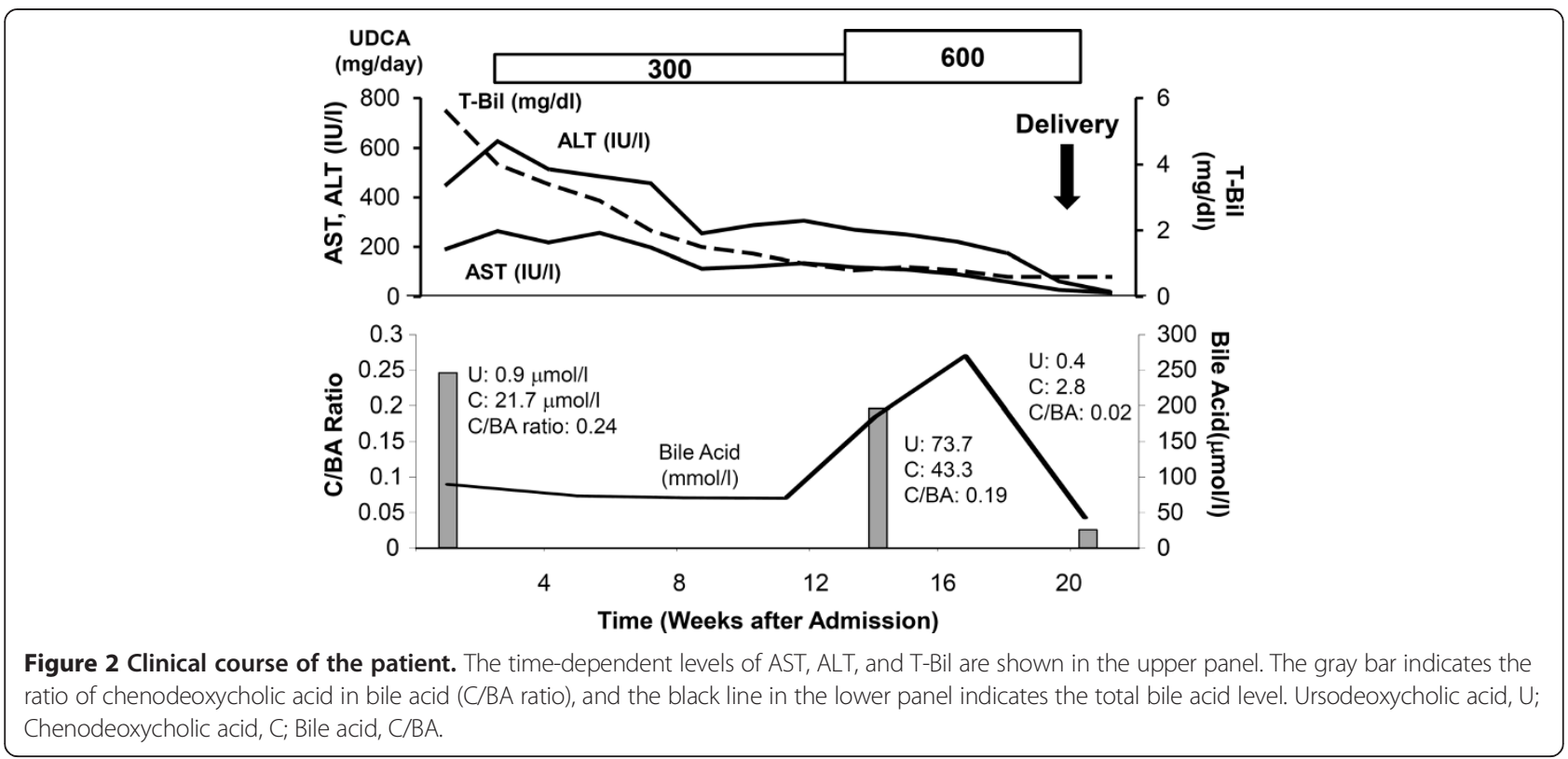

to severe type of ICP [14]. These genetic backgrounds might affect the expression of transporters and their structures that transport sulphated progesterone metabolites which significantly increases during pregnancy leading to the clinical symptoms [19]. Our case showed significant pruritis and increased levels of total and cytotoxic bile acids at the time of admission that was first trimester of pregnancy. Her serum markers showed no evidence of other hepatic diseases, such as HELLP syndrome, acute fatty liver of pregnancy, autoimmune liver diseases, or viral chronic hepatitis. The major SNP in $A B C B 11$ (1331 $\mathrm{T}>\mathrm{C}, \mathrm{rs} 2287622$ ) and the additional synonymous mutation in $A B C B 4(504 \mathrm{C}>\mathrm{T}, \mathrm{rs} 1202283)$ were confirmed by the genomic sequencing strategy. These results are indicating the potential relationship with the disease [14] and its severity [15], however since these variations have also been found in general population [16-18], the diagnosis of the disease based on the clinical symptoms and exclusion of other liver diseases like our case. Although a standard therapeutic method has not been established, two recent studies encouraged the administration of UDCA for ICP to reduce pruritis and improve hepatobiliary enzyme levels to reduce the risk of fetal death [20,21]. The therapeutic effect of UDCA has been reported from various aspects. It replaces cytotoxic bile acid, such as chenodeoxycholic acid into UDCA, directly. In addition, it increases the membrane transport expression, such as MDR3 and BSEP, leading to the stimulation of hepatobiliary excretion of progesterone disulphates that ameliorate pruritus and liver injury [19]. These effects contribute for the treatment of ICP $[20,21]$. In our case, UDCA was effective for improving symptoms, i.e., led to decreases in levels of hepatobiliary enzymes and the C/BA ratio, and prevented intrauterine death and meconium passage. The C/BA ratio was used to define the level of bile acid toxicity because the total bile acid level increased after the administration of UDCA followed by replacement with cytotoxic chenodeoxycholic acid. Further studies will help the understandings and the genetic diagnosis, because no need exists to perform liver biopsy as an interventional method to diagnose the disease. In addition, as it is also known that ICP recurs in subsequent pregnancy [2], it is important to be aware of the disease and its therapeutic options.

\section{Conclusion}

The risk of ICP has been reported to be populationspecific, and it is rare in the Japanese population. Here, we report the first Japanese case of ICP with severe symptoms and successfully treated with UDCA. The genetic sequence analysis also supported the diagnosis. Because genetic variation in $A B C B 4$ and $A B C B 11$ has also been reported in the Japanese population, we need to be aware of potential ICP cases in pregnant Japanese women although further studies are necessary.

\section{Consent}

Written informed consent was obtained from the patient for publication of this case report and any accompanying images.

\section{Competing interests}

The authors declare that they do not have a current financial arrangement or affiliation with any organisation that may have a direct interest in their work. 


\section{Authors' contributions}

$\mathrm{KK}, \mathrm{AH}$, and $\mathrm{KN}$ wrote manuscript and performed genetic analysis and treated patient. $Y Y, O K, Y K, Y K, E T$, and TK treated patient and baby. MM, TY, $M K, K H, K Y$, and MT treated patient and analyzed the data. OM, KY, MY, and KR performed the genetic sequence analysis. NM, KT, and AY designed and analysed all data. All authors read and approved the final manuscript.

\section{Acknowledgement}

We acknowledge Enago for the English language review.

\section{Author details}

${ }^{1}$ Division of Gastroenterology and Hepatology, Graduate School of Medical and Dental Sciences, Niigata University, 1-757 Asahimachido-ri, Chuo-ku, Niigata 951-8510, Japan. ²Department of Obstetrics and Gynecology, Niigata University Medical and Dental Hospital, 1-754 Asahimachido-ri, Chuo-ku, Niigata 951-8510, Japan. ${ }^{3}$ General Center for Perinatal, Maternal and Neonatal Medicine, Niigata University Hospital of Medical and Dental Sciences, 1-754 Asahimachido-ri, Chuo-ku, Niigata 951-8520, Japan. ${ }^{4}$ Department of Molecular Genetics, Graduate School of Medical and Dental Sciences, Niigata University, 1-757 Asahimachido-ri, Chuo-ku, Niigata 951-8510, Japan. ${ }^{5}$ Department of Gastroenterology and Hepatology, Saiseikai Niigata Daini Hospital, 280-7 Teraji, Nishi-ku, Niigata 950-1104, Japan.

Received: 27 May 2014 Accepted: 11 September 2014

Published: 13 September 2014

\section{References}

1. Dixon PH, Wadsworth CA, Chambers J, Donnelly J, Cooley S, Buckley R, Mannino R, Jarvis S, Syngelaki A, Geenes V, Paul P, Sothinathan M, Kubitz R, Lammert F, Tribe RM, Ch'ng CL, Marschall HU, Glantz A, Khan SA, Nicolaides K, Whittaker J, Geary M, Williamson C: A comprehensive analysis of common genetic variation around six candidate loci for intrahepatic cholestasis of pregnancy. Am J Gastroenterol 2014, 109:76-84.

2. Geenes V, Williamson C: Intrahepatic cholestasis of pregnancy. World J Gastroenterol 2009, 15:2049-2066.

3. Schutt VA, Minuk GY: Liver diseases unique to pregnancy. Best Pract Res Clin Gastroenterol 2007, 21:771-792.

4. Joshi D, James A, Quaglia A, Westbrook RH, Heneghan MA: Liver disease in pregnancy. Lancet 2010, 375:594-605.

5. Bacq Y: Liver diseases unique to pregnancy: a 2010 update. Clin Res Hepatol Gastroenterol 2011, 35:182-193.

6. Ahmed KT, Almashhrawi AA, Rahman RN, Hammoud GM, Ibdah JA: Live diseases in pregnancy: diseases unique to pregnancy. World $J$ Gastroenterol 2013, 19:7639-7646.

7. Geenes V, Chappell LC, Seed PT, Steer PJ, Knight M, Williamson C: Association of severe intrahepatic cholestasis of pregnancy with adverse pregnancy outcomes: A prospective population-based case-control study. Hepatology 2014, 59:1482-1491.

8. Marschall HU, Wikstrom Shemer E, Ludvigsson JF, Stephansson O Intrahepatic cholestasis of pregnancy and associated hepatobiliary disease: a population-based cohort study. Hepatology 2013, 58:1385-1391.

9. Schneider G, Paus TC, Kullak-Ublick GA, Meier PJ, Wienker TF, Lang T, van de Vondel $P$, Sauerbruch T, Reichel $C$ : Linkage between a new splicing site mutation in the MDR3 alias ABCB4 gene and intrahepatic cholestasis of pregnancy. Hepatology 2007, 45:150-158.

10. Floreani A, Carderi I, Paternoster D, Soardo G, Azzaroli F, Esposito W, Montagnani M, Marchesoni D, Variola A, Rosa Rizzotto E, Braghin C, Mazzella G: Hepatobiliary phospholipid transporter ABCB4, MDR3 gene variants in a large cohort of Italian women with intrahepatic cholestasis of pregnancy. Dig Liver Dis 2008, 40:366-370

11. Trauner $M$, Fickert $P$, Wagner M: MDR3 (ABCB4) defects: a paradigm for the genetics of adult cholestatic syndromes. Semin Liver Dis 2007, 27:77-98.

12. Floreani A, Carderi I, Paternoster D, Soardo G, Azzaroli F, Esposito W, Variola A, Tommasi AM, Marchesoni D, Braghin C, Mazzella G: Intrahepatic cholestasis of pregnancy: three novel MDR3 gene mutations. Aliment Pharmacol Ther 2006, 23:1649-1653.

13. Pauli-Magnus $C$, Lang $T$, Meier $Y$, Zodan-Marin T, Jung D, Breymann $C$ Zimmermann R, Kenngott S, Beuers U, Reichel C, Kerb R, Penger A, Meier PJ, Kullak-Ublick GA: Sequence analysis of bile salt export pump (ABCB11) and multidrug resistance $p$-glycoprotein 3 ( $A B C B 4, M D R 3)$ in patients with intrahepatic cholestasis of pregnancy. Pharmacogenetics 2004, 14:91-102.

14. Dixon PH, van Mil SW, Chambers J, Strautnieks S, Thompson RJ, Lammert F, Kubitz R, Keitel V, Glantz A, Mattsson LA, Marschall HU, Molokhia M, Moore GE, Linton KJ, Williamson C: Contribution of variant alleles of $A B C B 11$ to susceptibility to intrahepatic cholestasis of pregnancy. Gut 2009, 58:537-544

15. Keitel V, Vogt C, Haussinger D, Kubitz R: Combined mutations of canalicular transporter proteins cause severe intrahepatic cholestasis of pregnancy. Gastroenterology 2006, 131:624-629.

16. Kim SR, Saito Y, Itoda M, Maekawa K, Kawamoto M, Kamatani N, Ozawa S, Sawada J: Genetic variations of the $A B C$ transporter gene $A B C B 11$ encoding the human bile salt export pump (BSEP) in a Japanese population. Drug Metab Pharmacokinet 2009, 24:277-281.

17. Lang T, Haberl M, Jung D, Drescher A, Schlagenhaufer R, Keil A, Mornhinweg E, Stieger B, Kullak-Ublick GA, Kerb R: Genetic variability, haplotype structures, and ethnic diversity of hepatic transporters MDR3 (ABCB4) and bile salt export pump (ABCB11). Drug Metab Dispos 2006, 34:1582-1599.

18. Meier Y, Pauli-Magnus C, Zanger UM, Klein K, Schaeffeler E, Nussler AK, Nussler N, Eichelbaum M, Meier PJ, Stieger B: Interindividual variability of canalicular ATP-binding-cassette (ABC)-transporter expression in human liver. Hepatology 2006, 44:62-74.

19. Glantz A, Reilly SJ, Benthin L, Lammert F, Mattsson LA, Marschall HU: Intrahepatic cholestasis of pregnancy: Amelioration of pruritus by UDCA is associated with decreased progesterone disulphates in urine. Hepatology 2008, 47:544-551.

20. Chappell LC, Gurung V, Seed PT, Chambers J, Williamson C, Thornton JG: Ursodeoxycholic acid versus placebo, and early term delivery versus expectant management, in women with intrahepatic cholestasis of pregnancy: semifactorial randomised clinical trial. BMJ 2012, 344:e3799.

21. Bacq $Y$, Sentilhes $L$, Reyes HB, Glantz A, Kondrackiene J, Binder T, Nicastri PL, Locatelli A, Floreani A, Hernandez I, Di Martino V: Efficacy of ursodeoxycholic acid in treating intrahepatic cholestasis of pregnancy: a meta-analysis. Gastroenterology 2012, 143:1492-1501.

doi:10.1186/1471-230X-14-160

Cite this article as: Kamimura et al:: Successful management of severe intrahepatic cholestasis of pregnancy: report of a first Japanese case. BMC Gastroenterology 2014 14:160

\section{Submit your next manuscript to BioMed Central and take full advantage of:}

- Convenient online submission

- Thorough peer review

- No space constraints or color figure charges

- Immediate publication on acceptance

- Inclusion in PubMed, CAS, Scopus and Google Scholar

- Research which is freely available for redistribution 